\title{
Quality assurance and quality enhancement of the nursing curriculum - happy marriage or recipe for divorce?
}

\author{
Thea F. van de Mortel ${ }^{1}$, J ennifer L. Bird ${ }^{2}$, J ulienne I. Holt ${ }^{3}$, Maree A. Walo ${ }^{4}$ \\ 1. School of Health and Human Sciences, Southern Cross University, Australia. 2. Teaching and Learning Centre, Southern \\ Cross University, Australia. 3. Academic Skills Development Unit, Southern Cross University, Australia. 4. School of \\ Tourism and Hospitality Management, Southern Cross University, Australia
}

Correspondence: Thea van de Mortel. Address: PO Box 157, Lismore, NSW, 2480, Australia. Telephone: 61-266-203-305. E-mail: tvandemo@scu.edu.au

Received: December 30, 2011 Accepted: February 29, 2012 Published: August 1, 2012

DOI : 10.5430/jnep.v2n3p110 URL: http://dx.doi.org/10.5430/jnep.v2n3p110

\section{Abstract}

Background: This study investigated nurse academics' perceptions of a curriculum review process that married a 'top down’ quality assurance process with a ‘bottom up’ quality enhancement process in a Bachelor of Nursing curriculum.

Methods: Focus group interviews were held with seven nurse academics on two campuses of a regional Australian university. The data were analyzed thematically.

Results: Overall nurse academics found value in both the collegial sharing of ideas in the 'bottom up' unit review meetings and in the 'top down' unit reporting process. However their perceptions of the curriculum review process highlighted a number of tensions that clustered around the following main themes: clarity of communication, sensitivity/validity of review data, the impact of contextual factors, and the risk of ritualized practice.

Conclusions: These results highlight that quality assurance and quality enhancement processes can be married, but clear communication is needed about the purposes of the curriculum review process and its constraints, and a mechanism is required to close the quality feedback loop. Nursing academics need to take ownership of the process to find ways to work around contextual constraints that impact on the success of the curriculum review process.

\section{Key words}

Curriculum review, Quality assurance, Quality enhancement, Nurse education

\section{Introduction}

Australian universities typically have policies that require departments to conduct five yearly formal external curriculum reviews. Critics of this approach ${ }^{[1]}$, argue that 'five year summative data gathering frenzies for institutional or accreditation reviews' are insufficient, and that curriculum review deserves more 'scholarly, formative and developmental' processes that engage all stakeholders. The literature ${ }^{[2-5]}$ suggests that many university departments are engaging in additional formative, curriculum review processes through knowledge networks, curriculum teams, and 
collegial critical friends. However, Harvey and Williams ${ }^{[6]}$ suggest that 'internal [quality] processes are still developing and the link between external processes, internal processes and improvements in teaching and learning seem to be tenuous and patchy'.

At the heart of this issue is a question about the complex and different values and approaches that underpin notions of quality in higher education. Quality assurance (QA) and quality enhancement (QE) are two terms that are commonly used to describe the two main 'camps.' The major aim of quality assurance in higher education is to ensure that set teaching standards are met, and this type of quality is achieved through a management-driven focus on monitoring and reporting. Quality enhancement aims to improve the quality of teaching delivery and curriculum through a collaborative, capacity-building approach. Many authors in the quality field describe an intrinsic tension between QA and QE ${ }^{[7]}$ as they may focus on different things and utilise different mechanisms that may conflict (see Table 1).

Table 1. Comparison of quality assurance and quality enhancement

\begin{tabular}{|c|c|}
\hline Quality assurance & Quality enhancement \\
\hline Emphasizes monitoring and documentation & Emphasizes professional development and discussion ${ }^{[8]}$ \\
\hline Driven by management (top-down approach) & Driven by faculty (bottom-up approach) ${ }^{[8]}$ \\
\hline Focuses on the performance of the individual teacher & Focuses on improving collaboration between teachers ${ }^{[8,9]}$ \\
\hline Can become a ritual & Less likely to be ritualistic as it is owned by stakeholders ${ }^{[10]}$ \\
\hline Emphasizes accountability & Emphasizes improvement ${ }^{[9,10]}$ \\
\hline May be seen as impression management & Encourages real change ${ }^{[11]}$ \\
\hline Can lead to pragmatic acceptance & Encourages ownership and empowerment ${ }^{[11]}$ \\
\hline Rule-based & Flexible and evaluative ${ }^{[7]}$ \\
\hline A bureaucratic, administrative task & Improvement of academic endeavours ${ }^{[10]}$ \\
\hline
\end{tabular}

However, according to Filippaku and Tapper ${ }^{[7]}$, 'it is also possible to perceive of a positive, symbiotic relationship between the two concepts, that they are in effect interactive processes in the improvement of an institution's teaching and learning mission'. For example, QA procedures can tell us what needs improvement and QE can help us to achieve that improvement. Biggs ${ }^{[9]}$ divides QA into retrospective and prospective forms, suggesting the former makes a summative judgment about what has been done and is top down and bureaucratic, whilst the latter encourages continual improvement through QE processes.

This study explores nurse academics' perceptions of a curriculum review process that married QA and QE approaches. The curriculum review process under investigation was originally conceived as a 'bottom up', internal, QE process that aimed to stop 'curriculum drift' within the five year formal review cycle ${ }^{[12]}$ and protect the graduate attributes and nursing competencies that were designed into the accredited curriculum. The process, implemented in 2006, involved nurse academics meeting in curriculum teams by year of the course (the term course refers to the degree program) along with the Course Coordinator, representatives from the Teaching and Learning Centre, Academic Skills Development Unit and the Library, prior to and after each of two teaching periods in the University's academic year, to review the curriculum both as it was planned and enacted ${ }^{[13]}$ to see how improvements could be made. The process and its perceived outcomes are described by van de Mortel and Bird ${ }^{[12]}$.

During 2007 the University amended its Course Review Policy. The new policy, implemented in 2008, in an attempt to avoid the 'five year data gathering frenzy' ${ }^{[1]}$, borrowed from the continuous curriculum review process established by the Nursing Department by requiring academics to analyze and report on data collected about their units (subjects) at the end of each teaching session via a Unit Report. Unit assessors (the academic staff in charge of each unit) were asked to reflect Published by Sciedu Press 
on quantitative statistics collected institutionally on grade point average, attrition and student satisfaction ranked by teaching campus, and qualitative data from fellow teachers and students, as well as their own experience of teaching delivery in that unit.

Thus nursing staff experienced some parts of their 'bottom up' approach to curriculum review return to them as a 'top down' policy driven approach. The new policy did not require academics to meet in curriculum teams and engage in dialogue about the curriculum as nursing staff had been doing for several years, however the nursing staff carried on with their unit review meetings while also complying with the Unit Report process. This provided an opportunity to investigate whether the tensions between these approaches identified in the literature were present in this circumstance.

Thus the purpose of this study was to:

1) investigate nurse academics' perceptions of the curriculum review process;

2) investigate how their feelings about the process changed over time.

\section{Participants and methods}

\subsection{Subjects}

All academic staff in continuing positions that were a) involved in the delivery of the Bachelor of Nursing program at one regional Australian University and b) had also participated in the curriculum review process under study were invited to participate. Seven academic staff members from two campuses were interviewed, which represented $50 \%$ of eligible staff. The small non-representative sample may be seen as a limitation of the study.

\subsection{Study design}

In-depth, semi-structured focus group discussions were used to investigate nurse academics' perceptions of the curriculum review process and their responses to the process over time. Eligible academics were invited by an experienced external facilitator to participate in a focus group at their campus. Information for Participants and Informed Consent forms were issued to all potential participants, who were informed that participation was voluntary, that the data would be de-identified prior to being seen by the researchers, and that they could withdraw from the study at any time. The following semi-structured interview questions were used to stimulate discussion:

1) What aspects of the unit review process do you like? Why?

2) What aspects of the unit review process do you dislike? Why?

3) How has the unit review process made you feel and has the way you felt about the process changed over time?

A one-hour focus group was conducted at each of two campuses. Focus group discussions were audiotaped with participants' permission. The external facilitator transcribed and de-identified the data before forwarding the transcripts to the researchers.

\subsection{Ethical considerations}

The study was approved by the University's Human Research Ethics Committee (ECN-10-057), and conformed to the principles outlined in the Australian National Statement on Ethical Conduct in Human Research. 


\subsection{Data analysis}

The qualitative data software analysis package NVivo9 ${ }^{[14]}$ was used to code the data. The codes were generated by the researchers who looked for meaning and patterns in the data as described by Braun and Clarke ${ }^{[15]}$. Factors that were considered when selecting codes were prevalence in the data and the 'keyness' of the item in terms of the research question ${ }^{[15]}$. Similar or related codes were grouped together to form themes. The research team drew conclusions about the meanings of those themes to develop an explanation for the results.

\section{Results}

Five key themes are presented below and illustrated with quotations.

\subsection{Collegiality and structure valued}

Participants reported various advantages to them in both the formal, documented Unit Report and the additional non-policy driven collegial discussion engendered by the unit review meetings. They considered the advantages of the Unit Report to be that it provided:

a) a mechanism to examine trends in the data (student satisfaction, attrition, grade point average) over a period of time, 'I found that ability to be able to set up a trend over a number of years...really helpful'

b) a formal mechanism for documenting and reporting resource and unit delivery issues to management, 'it enables us, in a structured and formal way, to convey to those who are responsible for providing the appropriate resources for us, that there were some problems'

c) an historical record of how the unit had been delivered over time that new unit assessors could use to inform their approach to that unit, '[it] is useful because it's...a record. We do have changes in unit assessors quite often and [the new] unit assessor [is able] to pick up the travelling journey of [how] that unit's changed over time'

d) a means of monitoring whether the integrity of the planned curriculum remained intact, '[making] sure that what is being delivered reflects what we are setting out to deliver based on the objectives and the curriculum documents that we have had ticked off by relevant [professional accreditation] boards'

Participants also saw strengths in the unit review discussions, for example:

a) they enjoyed sharing ideas with, and getting feedback from, other academics,' I really like being in a group situation to discuss what worked and what didn't work so well and get feedback from your colleagues' 'you can get suggestions and work on changing the unit assessment ...to make the unit more valuable for the students' 'everybody gets to see how other people are doing things'

b) getting a wider picture of the students' assessment regime and how graduate attributes are developed across the course, 'this process allows me to see what other units are covering and how they're doing it...you get a better picture of how the graduate attributes are being developed'

c) developing a sense of ownership over quality improvement of the course rather than having changes enforced from above, 'it's a way of determining where the gaps lie and how to fix them and coming up with solutions as a group rather than things being enforced from above' 
d) mentoring newer teaching staff, 'you can assist people who are less experienced by making constructive comment on their feedback especially... if you're listening to what didn't work so well and you can then add what can you do next time... it's a much larger learning experience for more novice academics ... you can assist them and it becomes a nice mentoring type of process'

e) having the opportunity to get professional development on teaching and learning from a multi-disciplinary team, 'having someone from teaching and learning there...to help to cohese it really makes a difference ... [she has] really been able to keep her finger on what is happening and be able to give you suggestions about what you can do'.

\subsection{Clarity of communication}

Some participants perceived:

a) a lack of clarity about the purpose of the curriculum review process, 'what's the main objective, what are the reasons that we have retrospective unit reviews, what should the outcomes of that review be?' 'who is it for, you know is it teaching and learning, is it a university mandate directive or are we doing it for ...the bachelor of nursing?'

b) uncertainty about how the issues raised would be addressed, and who had carriage of them, 'I fill out the information and feedback to the unit assessors and get absolutely no feedback whatsoever of how they're going to be actioned....and what was the result of that action...until the following year [when the unit is delivered again]' 'these [reports] just get filed I think ... I know they are stored and I presume they are probably used in the quality review ... apart from being a benefit to me, and I find them particularly beneficial, I don't know what else happens to them to be quite honest'

c) a lack of clarity about what can be expected from the process in terms of the feedback from staff being actioned, or unit assessors being required to follow through on suggestions from the teaching team, 'there has been a number of occasions where I have fed in information and ...nothing changes' 'some individuals ... would perhaps manipulate a process knowing there is a process and pay lip service to it, you know but actually not change anything, because it doesn't suit their workload or something'

Participants suggested, 'there must be a defined outcome ... that gets fed back to everyone involved in the team of that unit not just the unit assessor, so it's the librarian and it is the casual teachers... that [these are] the problems that were identified, this is what we going to do about it, this is the time frame... and [who is] going to work on that.'

\subsection{Sensitivity/ validity of review data}

The Unit Report requires academics to analyze data from different stakeholders about each unit taught. However academics had mixed feelings about the evidentiary base required for the Unit Reports. One academic perceived the Unit Report questions to be 'skewed towards student opinion' and therefore subject to bias. Conversely another commented favorably that 'it's not just the unit coordinator who contributes it's the students who contribute in the review.' Another academic commented 'informal feedback from students can be good....but it's more comments from the teaching team, I think are more relevant as to how they have seen how the students have interacted with things and whether students have developed the skills that we're trying to get them to develop.'

Academics in this study also questioned the usefulness of analyzing the institutional quantitative data because 'you can't run any statistics on it because [the response rate is] far too small to be able to run anything meaningful'. Conversely, one academic commented 'I've set up the current and then the two previous years and I have a look at what happened over that 
period of time. I found that particularly helpful in providing insights into what might account for various aspects of the way the unit performed in the present time. So I found that ability to be able to set up a trend over a number of years...really helpful'. Another academic found the qualitative questions like 'What did you introduce that was new this year?' more valuable than the institutional quantitative data.

\subsection{The impact of contextual factors}

Participants identified some organizational and situational factors that they perceived as obstacles to the effectiveness of the unit review process. These were:

a) The logistics of organizing the participation of large teaching teams that included a high proportion of casual staff located on multiple campuses at distant locations. Whilst unit assessors were encouraged to invite their teaching team to attend the unit review meetings or provide written feedback for consideration, in practice casual staff rarely participated because ..., 'casuals in those other campuses, they're not involved ....their contract is finished'

b) Disengagement by academics at distant sites when compelled to communicate via teleconference, 'the main area that is chairing the meeting face-to-face, they start to have a dialogue and you start to feel totally excluded from the conversation'

c) The time commitment to properly engage in the process, 'so there's whole stuff around the timing, the convenience of getting people together when they've got teaching commitments, it's hard'

d) Chronic staff shortages meant that there were few continuing staff available to peer review assessment items, which was part of the collegial review process, 'we're so short staffed...we just don't have any staff. Finding someone who can actually peer review your assessment and give you some feedback and even check your exam before you put it in is like hen's teeth you know, you're fighting to actually find someone who is here who can actually do that'

e) The introduction of a third session to the University's teaching calendar resulting in shorter breaks between teaching sessions. The impact of this on the new 'rhythm' and timing of the unit review process meant that academics were well into their next teaching session when asked to review the last one, 'one lot is finishing and another lot is starting again in three weeks time, so you haven't got time to draw breath and if you are trying to bring in any changes between the one semester and the next we haven't got [much time]'

f) A pending complete new curriculum development process meant a loss of interest and impetus for changing and improving the existing one

\subsection{The risk of ritualized practice}

Some academics felt that something of value had been lost since the 'bottom up' review process was first implemented. What is clear is that some academics valued the opportunity for dialogue with colleagues very highly, and felt keenly the loss of that opportunity:

'[initially] the unit reviews I did were done actually face-to-face; everybody happened to be in the same room, and I found that actually much more beneficial to the process... it wasn't like the last one I went to where people filed in and gave their report and filed out again...I do realize it's about money and all those sorts of things but I just wonder whether we've lost some of the value' 
'there's times when I've done the unit review virtually one-on-one with the course coordinator because there wasn't any time that could fit in with any other unit assessors ...so it was just a one-on-one go through, tick the boxes, say that we've done it'

'I find it most frustrating because I just went in and gave my report and there was no one there to bounce any ideas off and these processes are really good if you can do it in a group situation because as I say there are things that people say that trigger you to maybe make a comment on'

'in the beginning it was all exciting and people thought, yes we'll make changes, we'll look at the whole picture, we'll see how we can alter things, but that has tapered off quite a bit I think and I don't feel like that impetus is there quite as much any more'

\section{Discussion}

Some aspects of the marriage between QA and QE processes worked well. Academics saw benefits in both the formal Unit Report and the collegial discussion generated during the unit review meetings. The QA approach provided a means of reporting delivery issues to management, a historical record of changes to the unit that could inform the decision making of new unit assessors and a means of monitoring for curriculum drift. The QE approach provided a means of capacity-building teaching skills through sharing of ideas and mentoring and also developed in academic staff a wider perspective of curriculum and development of graduate attributes. Van de Mortel and Bird ${ }^{[12]}$ previously identified capacity-building teaching skills through the sharing of ideas, mentoring new staff, encouraging reflective practice, and broadening the perspectives of academic staff from a focus on their own individual units to a sense of collective responsibility for the whole course with an appreciation of the development of graduate attributes across multiple units as potential benefits of this curriculum review process. Our results suggest that academics participating in the curriculum review process can also see those benefits. Bingham and Ottewill ${ }^{[3]}$ identified similar strengths in their collegial unit review process.

There were also some tensions apparent between the QA and QE processes. For example, academics expressed confusion about the overall purpose of the process (who is it for?), and this may be due to a conflict between the audit QA component, and the collegial capacity-building QE component. This tension could be resolved through better communication about the purpose of the curriculum review and unit reporting process, what happens to the data collected, how (and if) the suggested changes should be actioned and who would take carriage of those actions. Participants interviewed by Newton ${ }^{[16]}$ also raised poor communication during quality processes as an issue and the necessity to 'close the quality loop' by feeding information back to participants on the outcomes of the process. Similarly Bingham and Ottewill ${ }^{[3]}$ found that lack of clarity about the implementation of recommendations from the review process was a concern for their participants.

In addition, there appears to be an inherent tension in a process that on the one hand we wish to be agentic, capacity building, and formative (QE), that also has the potential to be punitive and authoritative if misused (QA). Some participants felt that other staff members were gaming the process, and were frustrated when their suggestions for adjustments to the units they taught into were not accepted or actioned by the unit assessor. Other authors also describe academics' perceptions that some staff play the game, get away with mock compliance, or find the quickest way around quality processes ${ }^{[11,17]}$ perhaps because it has 'no teeth' ${ }^{[18]}$, indicating some frustration amongst academics directed against those that they perceive are not playing by the rules. However, Filippaku and Tapper ${ }^{[7]}$ suggest that a draconian rule-based quality assurance process administered with a 'rod of iron' leaves no room for quality enhancement to occur, so there is a delicate balance between trying to develop a quality process that upholds standards while at the same time trying to allow academics the autonomy to develop their skills in a formative rather than coercive way. 
A specific tension engendered by the QA component, involved the requirement to report on statistics collected by the university on attrition, grade point average and student satisfaction. The diversity of responses suggests that academics are engaging with data through the lens of their own epistemological backgrounds and values. The responses demonstrate mixed preferences between the value of student and teacher feedback, and a general mistrust of the validity and meaningfulness of the institutionally gathered quantitative data. Similarly, British academics were also concerned about the sensitivity of the data that were used to audit quality in higher education ${ }^{[18]}$. Jones ${ }^{[6]}$ argues in favor of the model investigated here by suggesting that quantitative data collected by the institution should be supplemented with qualitative data from individual units for the best outcome. Academics may feel more confident about the process if they understood better that the various types of data collected from different stakeholders were all relevant, and provided better opportunities to triangulate and validate 'what is going on' than any one individual source of data that may be weak in isolation.

Situational constraints impacted on the ability of staff to get the best outcomes from the QE curriculum review meetings. Other studies have found similarly ${ }^{[11,19-21]}$. Newton ${ }^{[11]}$ argued that with regard to policies in the quality arena there is an 'implementation gap' between what is designed and the situational variables that prevent the policy from being achieved. For example, he suggests that 'situational pressures' such as high workloads, and lack of proper staffing 'militate against meaningful teamwork' ${ }^{[16]}$. Newton ${ }^{[11]}$ also argues that the development and implementation of policies associated with quality are complex and should be viewed as iterative rather than defined end points. Biggs ${ }^{[9]}$ argues that institutions need to make quality initiatives feasible by removing impediments to good teaching. Whilst some of the obstacles identified in this study are beyond the control of the nursing academics, others can be tackled by the staff who can make adjustments to the process.

Participants indicated that something of value had been lost due to changes in the way the quality processes were administered over time. They felt as though the process had become a ritual that had to be complied with to tick-a-box rather than something that had meaning and value to them. It is not clear whether this loss of value was attributed to the formalizing of the Department's ‘bottom up’ QE process into ‘top down' policy or the cumulative impact over time of the contextual issues described above or a mixture of both. Comments such as these resonate with some of Newton's ${ }^{\text {[11] }}$ dimensions of the policy 'implementation gap' referred to earlier, for example the difference between academics engaging in a meaningful QE process versus academics ritualistically 'feeding the beast' of QA policy requirements. Similar issues were also raised by British academics who described 'a tickbox mentality' towards quality audits ${ }^{[18]}$. Duening and Kadipasaoglu ${ }^{[22]}$ found three principles that were essential to the success of their particular team-based quality initiative: dialogue, enjoyment and trust. It would appear that at least some academics involved in this study felt that over time there had been a diminution in these elements, and that the process had suffered as a result.

Given that Knight ${ }^{[23]}$ argues that professional learning is 'largely non-formal, social and situated' in the lived environment rather than a function of formal professional development opportunities run by a teaching and learning unit, a formative quality enhancement process that encourages exchange of ideas and experiences between academic staff offers an important opportunity to capacity-build academics' teaching skills and mentor new staff. Biggs ${ }^{[9]}$ also strongly emphasizes the importance of knowledge sharing between academics as a means of enhancing the quality of teaching, suggesting that 'a genuine sharing of problems and solutions' viewed through the lens of a quality model can lift the performance of a whole department in a way that the traditional focus on the individual as teacher cannot.

\section{Conclusion}

Academics in this study found much to like in this particular marriage between QA and QE processes. For example, they liked the formal structured approach for reporting on teaching delivery issues and collecting historical data to examine trends in unit delivery. They also felt that the curriculum review process encouraged collegial sharing of ideas, mentoring 
for newer academics and gave academic staff a better appreciation of student load and the development of graduate attributes across the course. However some tensions between the two processes are apparent in these data. Changes to the curriculum review process over time led to some perceptions that it had become a tick-a-box process, although it is unclear how much of this dissatisfaction was due to situational factors that acted as impediments to full academic engagement in the process, and how much was due to the bottom up approach to curriculum review being married to a top down audit approach. It is clear that if the process is not to end in divorce, more attention needs to be given to setting up clear expectations of what the process can and cannot deliver, what happens to the information collected, and a clear process for feeding back to participants what the outcomes of their feedback are and how and by whom they will be implemented. Additionally, nursing academics need to take ownership of the process to find ways to work around situational constraints that impact on the success of the curriculum review process so that they can regain the value of the collegial sharing of ideas that some feel has been lost over time.

\section{References}

[1] Hubbell H, Gold N. The scholarship of curriculum practice and undergraduate program reform: integrating theory into practice. New Directions for Teaching and Learning. 2007; 112: 5-14. http://dx.doi.org/10.1002/tl.293

[2] Jurdens JZ, Zepke N. A network approach to curriculum quality assessment. Quality in Higher Education. 2009; 15: 279-289. http://dx.doi.org/10.1080/13538320903399125

[3] Bingham R, Ottewill R. Whatever happened to peer review? Revitalising the contribution of tutors to course evaluation, Quality Assurance in Education. 2001; 9: 32-39. http://dx.doi.org/10.1108/09684880110381319

[4] Radloff A. Decentralised approaches to education development: supporting quality teaching and learning from within the faculty. In Education Development and Leadership in Higher Education. K. Fraser, ed. London: Routledge Falmer. 2004.

[5] Hill A. Continuous curriculum assessment and improvement: A case study. New Directions for Teaching and Learning. 2007; 112: 33-45. http://dx.doi.org/10.1002/tl.296

[6] Harvey L, Williams J. Fifteen years of quality in higher education (Part Two), Quality in Higher Education. 2010; 16: 81-113. http://dx.doi.org/10.1080/13538322.2010.485722

[7] Filippakou O, Tapper T. Quality assurance and quality enhancement in higher education: contested territories? Higher Education Quarterly. 2008; 62: 84-100. http://dx.doi.org/10.1111/j.1468-2273.2008.00379.x

[8] Swinglehurst D, Russell J, Greenhaigh T. Peer observation of teaching in the online environment: an action research approach. Journal of Computer Assisted Learning. 2008; 24: 383-393. http://dx.doi.org/10.1111/j.1365-2729.2007.00274.x

[9] Biggs J. The reflective institution: Assuring and enhancing the quality of teaching and learning. Higher Education. 2001; 41: 221-238. http://dx.doi.org/10.1023/A:1004181331049

[10] Harvey L, Williams J. Fifteen years of quality in higher education. Quality in Higher Education. 2010; 16: 3-36. http://dx.doi.org/10.1080/13538321003679457

[11] Newton J. Feeding the beast or improving quality? Academics' perceptions of quality assurance and quality monitoring. Quality in Higher Education. 2000; 6: 153-163. http://dx.doi.org/10.1080/713692740

[12] van de Mortel T, Bird J. Continuous curriculum review in a Bachelor of Nursing course: preventing curriculum drift and improving quality. Journal of Nursing Education. 2010; 49: 592-595. http://dx.doi.org/10.3928/01484834-20100730-05

[13] Barnett R, and Coate K. Engaging the curriculum in higher education. Berkshire: SRHE and Open University Press, 2005.

[14] QSR International Limited. NVivo9 [computer software]. Victoria, Australia: QSR International Limited, 2011.

[15] Braun V, Clarke V. Using thematic analysis in psychology. Qualitative Research in Psychology. 2008; 3: 77-101. http://dx.doi.org/10.1191/1478088706qp063oa

[16] Newton J. Feeding the beast or improving quality? Academic staff perceptions of quality assurance and quality monitoring [Internet]. 1998; Paper presented at Higher Education Close Up, 6-8 July, Preston, United Kingdom. Available from: http://www.leeds.ac.uk/educol/documents/000000684.htm

[17] Cheng M. The perceived impact of quality audit on the work of academics. Higher Education in Research \& Development. 2011; 30: 179-191. http://dx.doi.org/10.1080/07294360.2010.509764

[18] Teelken C, Lomas L. "How to strike the right balance between quality assurance and quality control in the perceptions of individual lecturers": a comparison of UK and Dutch higher education institutions. Tertiary Education and Management. 2009; 15: 259-275. http://dx.doi.org/10.1080/13583880903073016 
[19] Mayes T, Morrison D, Mellar H, Bullen P, Oliver M. (eds) Transforming higher education through technology-enhanced learning. United Kingdom: The Higher Education Academy, 2009.

[20] Newton J. Views from below: Academics coping with quality. Quality in Higher Education. 2002; 8: 39-61. http://dx.doi.org/10.1080/13538320220127434

[21] Harvey L. A history and critique of quality evaluation in the UK. Quality Assurance in Education. 2005; 13: 263-276. http://dx.doi.org/10.1108/09684880510700608

[22] Duening T, Kadipasaoglu SN. Team-driven change in higher education: The three key principles, Quality in Higher Education. 1996; 2: 57-64. http://dx.doi.org/10.1080/1353832960020106

[23] Knight P. Quality enhancement and educational professional development. Quality in Higher Education. 2006; 12: 29-40. http://dx.doi.org/10.1080/13538320600685123 